\title{
RIGHT-SIDED PNEUMOTHORAX IN A PATIENT WITH CHRONIC OBSTRUCTIVE PULMONARY DISEASE AND TUBERCULOSIS-AFFECTED LEFT LUNG: A CASE REPORT
}

\author{
Velizar Hadzhiminev ${ }^{1}, K_{\text {rasi Kalacheva }}^{2}$, Atanas Batashki', Angel Uchikov ${ }^{1}$, Ivan Novakov \\ ${ }^{1}$ Department of Special Surgery, Faculty of Medicine, Medical University - Plovdiv \\ ${ }^{2}$ Department of Medical Oncology, Central Onco Hospital, Plovdiv
}

\begin{abstract}
INTRODUCTION: A spontaneous pneumothorax occurring in a patient with underlying lung pathology is classified as a secondary spontaneous pneumothorax (SSP). Its main cause is the chronic obstructive pulmonary disease (COPD), more rarely - a tuberculosis infection (TB). Untreated TB could lead to carnification of a part or the whole lung.

CASE REPORT: A 35-year-old female patient was admitted with complaints of sudden right chest pain and severe dyspnea. The physical examination showed retracted and deformed left chest part, missing breathing sounds in the left and weakened breathing in the right. Chest CT revealed partial right-sided pneumothorax, bullous changes of the right lung and carnification of the whole left lung. Right thoracocentesis was performed. The postoperative period was uneventful. The chest drain was removed on the fifth day. After more detailed examinations the patient was diagnosed with COPD and TB and was transferred to the Department of Pulmonology and Phthisiatry for further treatment.
\end{abstract}

CONCLUSION: In a patient who has two advanced and complicated lung diseases at the same time (COPD and TB), a spontaneous pneumothorax, even partial, is a life-threatening condition and requires special consideration and urgent therapeutic measures.

Keywords: spontaneous pneumothorax, lung carnification, COPD, pulmonary emphysema, pulmonary tuberculosis

Address for correspondence:

Velizar Hadzhiminev

Department of Thoracic and Abdominal Surgery

University Hopsital "Sveti Georgi"

66 Peshtersko shosse Blvd

4001 Plovdiv, Bulgaria

e-mail:v.hadjiminev@abv.bg

Received: July 8, 2018

Accepted: September 4, 2018

\section{INTRODUCTION}

A spontaneous pneumothorax occurred in a patient with underlying lung pathology is classified as a secondary spontaneous pneumothorax (SSP) (1). Its main cause is the chronic obstructive pulmonary disease (COPD) together with pulmonary emphysema. Tuberculosis (TB) is also a well-known cause, especially in endemic areas (2). SSP requires a special consideration because of the life-threatening symp- 
Right-Sided Pneumothorax in a Patient with Chronic Obstructive Pulmonary Disease and Tuberculosis-Affected Left Lung: A Case Report

toms, the various locations of ruptured bullae and the high recurrence rate and mortality, even if surgery is performed. It needs timely treatment that includes thoracocentesis, video-assisted thoracoscopy (VATS) pleurodesis and thoracotomy $(3,4)$.

\section{AIM}

The aim of this case is to show the simultaneous presentation of two advanced lung diseases COPD and TB together with life-threatening emergency - SSP.

\section{CASE REPORT}

A 35-year-old female patient was admitted to the Department of Thoracic and Abdominal Surgery of University Hospital "Sveti Georgi" with complaints of sudden right chest pain, severe dyspnea and productive cough for 3 hours. Physical examination revealed no fever, pale skin, orthopneic position, retracted and deformed left chest part, missing breathing sounds in the left and weakened breathing in the right. She informed about lung problems in childhood without any previous treatment. Relevant laboratory findings at the time of admission were following: HGB - 99g/L; RBC - 3.62; WBC - 17.18; PLT - 534; glucose $6.2 \mathrm{mmol} / \mathrm{L}$; t. protein $-81 \mathrm{~g} / \mathrm{L}$; PT - 91.6\%. A CT scan revealed a partial right-sided pneumothorax, bullous changes of the apical part of the right lung with adhesions; the left lung was presented hypoplastic with carnification (atelectasis) as a result of post-inflammatory changes (Fig. 1,2,3). Right-sided thoracocentesis with the placement of a drain tube was performed under intravenous anesthesia monitored by an anesthesiologist. The control X-rays on the next day showed a fully expanded right lung (Fig. 4). The conservative treatment of the patient consisted of broad-spectrum antibiotic (Levofloxacin), expectorants, analgetics, low-molecular heparin and oxygen. The postoperative period was uneventful. The chest drain tube was removed on the fifth day after control X-ray. Spirometry results were as follows: FVC - 1.37 (39\%); FEV1 - 0.75 (25\%); FEV/FVC - 66\%. After consultation with pulmonologist and phthisiatry specialist the patient was transferred to the Department of Pulmonology and Phthisiatry for further diagnosis and treatment COPD and TB were discussed as possible comorbidities. A bronchodilator test revealed not fully revers-

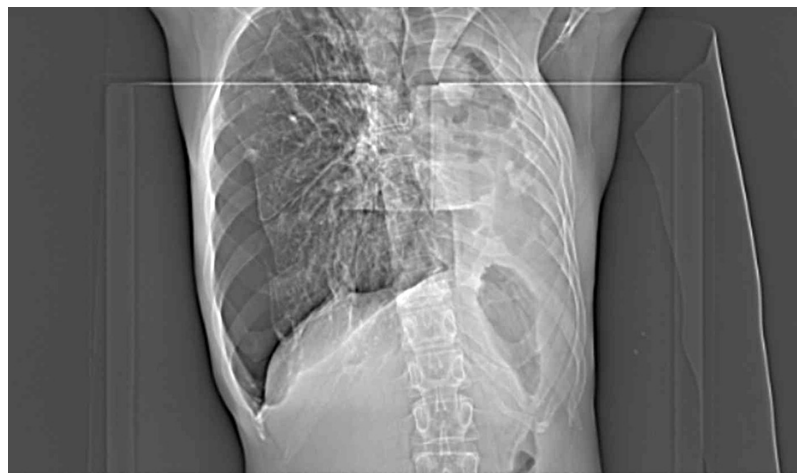

Fig. 1. Partial right-sided pneumothorax with carnification of the left lung

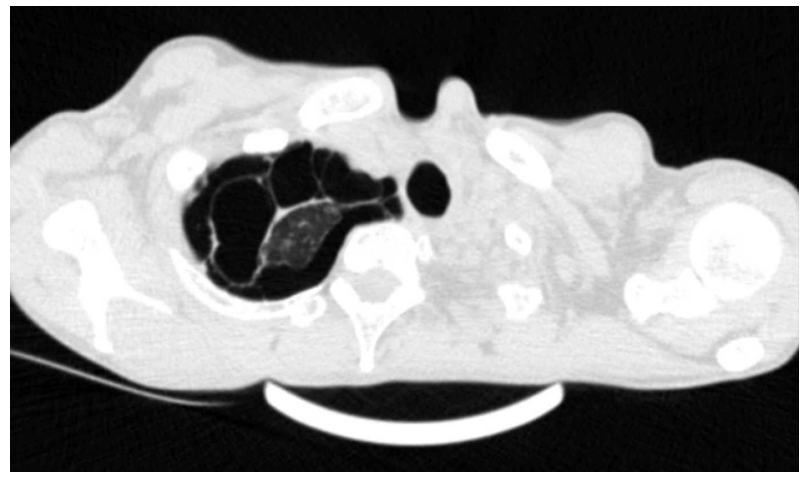

Fig. 2. CT image of bullous changes of the right lung

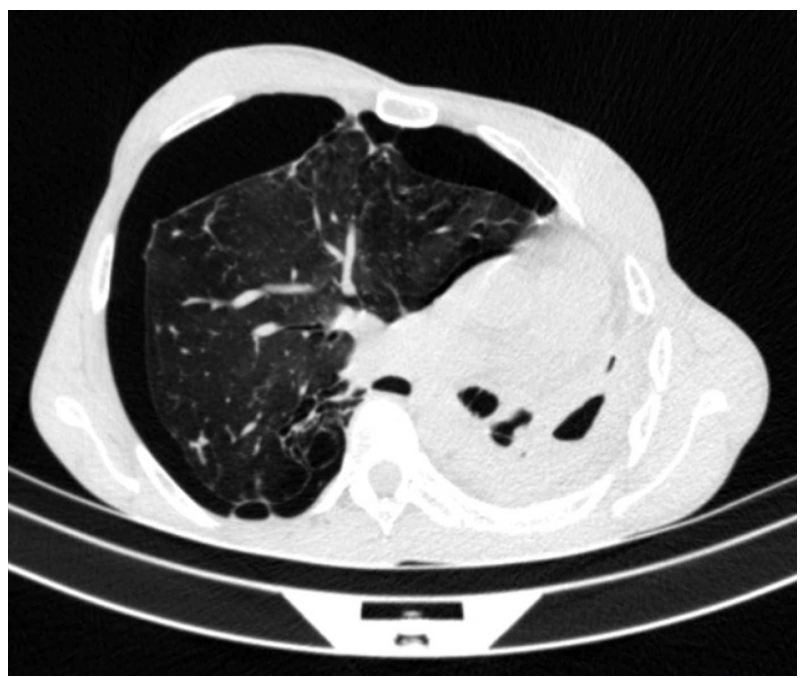

Fig. 3. CT image of pneumothorax and carnification

ible airflow limitation - an evidence of COPD. Laboratory results showed also that the patient was suffering from active pulmonary tuberculosis (positive direct Ziel-Nielsen microscopy and positive TB spot serologic test). 
Velizar Hadzhiminev, Krasi Kalacheva, Atanas Batashki et al.

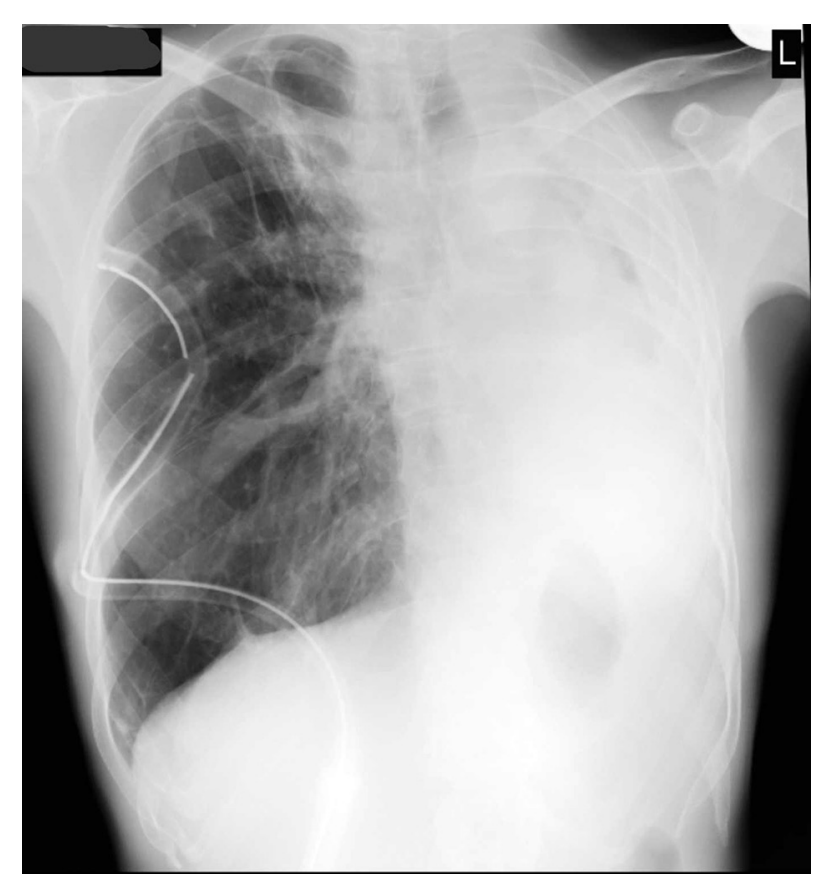

Fig. 4. X-ray image after the thoracocentesis

\section{DISCUSSION}

Secondary spontaneous pneumothorax is a common pathology in patients with COPD where bullous changes of the lungs are often observed due to pulmonary emphysema. It is more common in elderly patients $(5,6)$. The mean age is 55 years and men are more affected than women (7). SSP more often requires surgical treatment and has high rates of recurrence and mortality. Surgery includes thoracocentesis, VATS or open thoracotomy with pleurectomy and pleurodesis $(8,9)$.

Tuberculosis (TB) is known to cause a wide variety of complications and atypical presentations. It usually presents with typical symptoms. Pulmonary complications of TB are pleural effusion, empyema, bronchopleural and bronchopulmonary fistulas and pneumothorax $(10,11)$. Lung carnification (acquired atelectasis) is a serious complication of untreated or recurrent TB infection that could affect part or a whole lung and it has unfavourable long-term consequences (12-14).

In our case we present a young female patient with untreated TB and COPD that was admitted for a partial right-sided pneumothorax. COPD is not a common pathology for a 35-year-old woman, therefore the possibility of congenital disease or develop- mental anomalies should be considered - bronchiectasis, cystic fibrosis, alphal antitrypsin deficiency, polycystic lung disease. The respiratory problems during the patient's childhood support this suggestion. Unfortunately the patient did not present any previous medical documentation that could prove or reject these suggestions so further examinations would be required. The complete carnification of her left lung may be associated with developmental anomalies or untreated TB infection. The active tuberculosis was either recurrent or it had developed on the basis of a severely damaged lung. As a result, the left lung was with absent functional capacity. On the other side her only functioning right lung was with very limited breathing abilities due to the advanced pulmonary emphysema with diffuse bullous changes (COPD). These disorders were well presented on the CT scan and spirometry. The right-sided pneumothorax that had occurred, probably was not related to TB but to the bullous changes. Even partial, it additionally compromised her only breathing lung. This made it a life-threatening event that required immediate surgical treatment. We performed a thoracocentesis, placing chest tube in the 5th intercostal space under the monitoring of anesthesiologist prepared for intubation if any further complications occurred.

Reviewing the medical literature, our case is one of a few of its kind and this makes it valuable.

\section{CONCLUSION}

In a patient who has two advanced and complicated lung diseases at the same time - TB with carnification and COPD with bullous changes, a spontaneous pneumothorax, even partial, is a life-threatening condition and requires special consideration and urgent therapeutic measures.

\section{REFERENCES}

1. Van Schil PE, Hendriks JM, De Maeseneer MG, Lauwers PR. Current management of spontaneous pneumothorax. Monaldi Arch Chest Dis. 2005;63(4):204-12. doi: 10.4081/monaldi.2005.622.

2. Byrne AL, Marais BJ, Mitnick CD, Lecca L, Marks GB. Tuberculosis and chronic respiratory disease: A systematic review. Int J Infect Dis. 2015;32:13846. doi: 10.1016/j.ijid.2014.12.016. 
Right-Sided Pneumothorax in a Patient with Chronic Obstructive Pulmonary Disease and Tuberculosis-Affected Left Lung: A Case Report

3. Nakajima J. Surgery for secondary spontaneous pneumothorax. Curr OpinPulm Med. 2010;16(4):376-80. doi: 10.1097/ MCP.0b013e32833a3d96.

4. MacDuff A, Arnold A, Harvey J, BTS Pleural Disease Guideline Group. Management of spontaneous pneumothorax: British Thoracic Society pleural disease guideline 2010. Thorax. 2010;65 Suppl 2:ii18-31. doi: 10.1136/thx.2010.136986.

5. Agarwal R, Aggarwal AN. Bullous lung disease or bullous emphysema? Respir Care. 2006;51(5):532-4.

6. Smith BM, Austin JHM, Newell JD, D'Souza BM, Rozenshtein A, Hoffman EA, et al. Pulmonary emphysema subtypes on computed tomography: The MESA COPD study. Am J Med. 2014;127(1):94.e723. doi: 10.1016/j.amjmed.2013.09.020.

7. Bobbio A, Dechartres A, Bouam S, Damotte D, Rabbat A, Régnard JF, et al. Epidemiology of spontaneous pneumothorax: Gender-related differences. Thorax. 2015;70(7):653-8. doi:10.1136/ thoraxjnl-2014-206577.

8. Hobbs BD, Foreman MG, Bowler R, Jacobson F, Make BJ, Castaldi PJ, et al . Pneumothorax risk factors in smokers with and without chronic obstructive pulmonary disease. Ann
Am Thorac Soc. 2014;11(9):1387-94. doi: 10.1513/ AnnalsATS.201405-224OC.

9. Fettal N, Taleb A. Pneumothorax secondary to chronic obstructive pulmonary disease. Eur Respir J. 2012; 40(56): P558.

10. Qi Z, Yang W, Wang YF. Epidemiological analysis of pulmonary tuberculosis in Heilongjiang Province China from 2008 to 2015. Int J Mycobacteriology. 2017;6(3):264-7. doi: 10.4103/ijmy.ijmy_104_17.

11. Rawal G, Yadav S, Garg N, Wani UR. Secondary spontaneous pneumothorax (SSP) with bronchopleural fistula in a patient with COPD. J Clin Diagn Res. 2015; 9(4): PD07-8. doi: 10.7860/ JCDR/2015/13265.5807.

12. Adler D, Richards WF. Consolidation in primary pulmonary tuberculosis. Thorax. 1953;8(3):223-41.

13. Huang $X, X u X, Y u$ C, Fan R, Lu Y, Lu S, et al. Pulmonary sequestration with tuberculosis confined to the sequestrated lung. Ann Thorac Cardiovasc Surg. 2012;18(1):51-5.

14. Upadhyay GP, Thakker RM. Spontaneous pneumothorax - a clinical study of 100 cases. Int J Med Sci Public Health. 2017; 6(1):154-8. 